\title{
Low Hemoglobin Levels in Infected Diabetic Foot Ulcer
}

\author{
Isam Noori Salman ${ }^{1}$, Shatha Abdul Wadood ${ }^{* 2}$, Banan Akram Abualkasem ${ }^{3}$ \\ ${ }^{1}$ (College of Medicine/ Al-Mustansiriya University, Baghdad, Iraq) \\ 2, 3 (Department of Chemistry, College of Science / University of Baghdad, Baghdad, Iraq)
}

\begin{abstract}
Background: Studies have shown that anemia is twice as common in diabetics compared with nondiabetics. Objective: We aimed to evaluate the prevalence of anemia in diabetic foot ulceration (DFU) patients and it's correlation with infection. Methods: This study was conducted from October 2015 to the end of February 2016 and consisted of (55) Iraqi diabetic patients with foot ulcer that sub grouped to patients with non infected diabetic foot patients ( $n=25$, group NIDFU), and patients with infected diabetic foot $(n=30$, group $I D F U)$ according to erythrocyte sedimentation rate (ESR). Anthropometric indices and clinical examinations were done. Anemia is defined according to WHO as hemoglobin $(\mathrm{Hb})$ levels $<12 \mathrm{~g} / \mathrm{dL}$. Statistical analysis was done using t-test and Pearson correlation. Results: ESR of group NIDFU $(25.2 \pm 14.26 \mathrm{~mm} / \mathrm{hr})$ was significantly lower $(P=<0.001)$ in comparison to that of group IDFU $(76.73 \pm 33.39 \mathrm{~mm} / \mathrm{hr})$. The mean values of $\mathrm{Hb}$ of NIDFU group $(13.45 \pm 2.15 \mathrm{~g} / \mathrm{dl})$ was significantly higher $(P=<0.001)$ than that of IDFU group $(11.34 \pm 2.17$ $\mathrm{g} / \mathrm{dl}$ ). In IDFU group; $63 \%$ were anemic while only $32 \%$ of NIDFU group have anemia. Pearson correlation of ESR in IDFU group revealed significant negative correlation with $\mathrm{Hb}(r=-0.386 ; P<0.05)$, while no significant correlation with $\mathrm{Hb}(r=0.404 ; P>0.05)$ was found in NIDFU group. Conclusion: This prospective study showed a high incidence of anemia in patients with IDFU in contrast to NIDFU and a negative correlation was found between anemia and infection. Iron replacement and therapeutic strategies are recommended.
\end{abstract}

Keywords: diabetic foot ulcer, infection, hemoglobin, erythrocyte sedimentation rate.

\section{Introduction}

T Diabetic Foot Ulcer (DFU) is one of many complications that accompanying fifteen percent of patients with diabetes mellitus. Amputation is recurrently the final event of serious diabetic foot ulcer ${ }^{[1,2]}$. The prone of DFU to frequent chronic infection have an effect on the psychological health of the patient ${ }^{[3]}$. Disease of the peripheral nerves is known in diabetic patients and the management relies upon which nerve(s) is/are predisposed, this may include the peripheral nerves, the cranial and the autonomic nerves leading to numbness in the legs and may promote ulcer formation. When this problem is untreated, gangrene and amputation of the infected leg is provoked ${ }^{[4]}$. Diabetic nephropathy and retinopathy were associated with anemia for relatively some time ${ }^{[5,6]}$. Wound healing is impaired by anemia. In the face of underlying arterial insufficiency, anemia may sudden rest pain. Few studies investigate the association between anemia and DFU that were limited to renal anemia in diabetes ${ }^{[6,7]}$. Conway et al. $(2009)^{[8]}$ had proposed a mechanism is that hypoxia stimulate erythropoietin production that increase $\mathrm{Hb}$ level cause microvascular disease in both kidneys and retina of diabetic patients. According to some studies, hyperglycemia induces variation in hematological parameters ${ }^{[9,10]}$. Erythrocyte shape is affected by glucose levels in blood that manipulate their flow properties and insulin level is frequently change blood viscosity ${ }^{[9]}$. Infection can indicate quick onset and advancement in diabetic foot ulcers. In day by day clinical practice, systemic markers of infection are the most settled method for supporting the clinical suspicion of infection in DFU. The traditional markers in this setting incorporate leukocyte count and Creceptive protein (CRP) and also the erythrocyte sedimentation rate (ESR). Existence of all markers of systemic inflammation (for example ESR) was found in T2DM patients ${ }^{[11]}$. In this study, we aimed to evaluate the prevalence of anemia in diabetic foot ulceration (DFU) patients and it's correlation with infection. The analytic precision of ESR, as inflammation marker, was evaluated to discriminate between infected and non-infected DFU. Hemoglobin levels were measured to diagnose the presence of anemia in patients with DFU.

\subsection{Patients}

\section{Patients and Methods}

This study took place between October 2015 and the end of February 2016 and involved (55) patients with DFU were chosen from National Diabetes Center/Al-Mustansiyria University, National Center of Hematology and Al-Yarmuk teaching hospital in Baghdad city/Iraq. T2DM is diagnosed and classified according to the American Diabetes Association criteria (2015) (FSG $\geq 126 \mathrm{mg} / \mathrm{dl}$ or $2 \mathrm{~h}$ postprandial glucose $\geq 200 \mathrm{mg} / \mathrm{dl}$ ) ${ }^{[12]}$. Study groups consisted of patients with non-infected diabetic foot (group NIDFU; $\mathrm{n}=25$ ), patients with infected diabetic foot (group IDFU; $n=30$ ). Diabetic foot ulcer was defined as redness, swelling of 
wound, pus spots or exudates from the wound, fever, pain in the infected area, a full depth wound, and skin necrosis or gangrene below the ankle. All of the DFUs were graded using Wagner classification ${ }^{[13]}$, as shown in table (1). The purpose of the study was informed to all participants and their oral consent was acquired. Demographic information (age, gender, body mass index, and duration of T2DM) with detailed history were recorded in well-structured questionnaire. Complete clinical examination for every patient was done by specialist physician in the center. Anemia is defined according to the World Health Organization (WHO) criteria ${ }^{[14]}$, as hemoglobin $(\mathrm{Hb})$ concentration of less than $13 \mathrm{~g} / \mathrm{dL}$ in men and less than $12 \mathrm{~g} / \mathrm{dL}$ in women.

Table 1: Distribution of diabetic foot ulceration according to Wagner classification

\begin{tabular}{|c|c|c|c|c|c|}
\hline \multirow{2}{*}{\multicolumn{2}{|c|}{ Grade }} & \multicolumn{2}{|c|}{ NIDFU group } & \multicolumn{2}{|c|}{ IDFU group } \\
\hline & & No. & $\%$ & No. & $\%$ \\
\hline \multicolumn{2}{|l|}{0} & 5 & 17 & - & - \\
\hline \multicolumn{2}{|l|}{1} & 13 & 43 & - & - \\
\hline \multicolumn{2}{|l|}{2} & 12 & 40 & - & - \\
\hline \multicolumn{2}{|l|}{3} & - & - & 15 & 60 \\
\hline \multicolumn{2}{|l|}{4} & - & - & 4 & 16 \\
\hline \multirow[b]{3}{*}{ 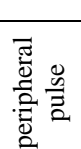 } & 5 & - & - & 6 & 24 \\
\hline & Positive & 27 & 90 & 20 & 80 \\
\hline & Negative & 3 & 10 & 5 & 20 \\
\hline
\end{tabular}

\subsection{Laboratory Analysis}

About 5 milliliters of venous blood was taken from all participants after an overnight fasting 10-12 hours. For measuring ESR, HbA1c and RBC, blood sample was transferred into EDTA tube. ESR was measured using Westergren tube. CBC count was measured using autoanalyzer device (Abbott, U.S.A). HbAlc was measured using commercial kit, (SDA1cCareTM, SD Biosensor, Germany). Serum blood was processed for the measurement of fasting serum glucose (FSG) using autoanalyzer device (Biolabo, France). Lipid profile [Total Cholesterol (TC), Triglyceride (TG), High-Density Lipoprotein-Cholesterol (HDL-C)] were measured using commercial kits (Biolabo, France). Friedewald's equation ${ }^{[15]}$ was used to calculate Low-Density LipoproteinCholesterol (LDL-C) and Very Low-Density Lipoprotein-Cholesterol (VLDL-C).

\subsection{Statistical Analysis}

Analysis of the results was completed utilizing the statistical package of SPSS (Statistical Packages for Social Science -Version 22). Data was presented as mean and standard deviation ( \pm SD). Independent student's t-test was used for comparison between two means. The correlation between two quantitative variables was presented in scatter diagram of the distribution, with the Bivariate Pearson's correlation coefficient (r) calculation and its significance. Significance difference was considered whenever the $P$ value was less than 0.05 . While high significant was considered whenever $P$ value was less than 0.01 .

\section{Results}

The clinical analysis of the two groups was presented in Table 2. ESR and PLT were significantly higher in IDFU group $(P<0.01)$ than those of NIDFU. While, RBC, Hb and PCV in IDFU group were significantly lower $(\mathrm{P}<0.01)$ when compared with that of NIDFU. Anemia in IDFU group represent $63 \%$ while it was $32 \%$ in NIDF patients, in spite of nephropathy in NIDFU group was $20 \%$ while it was only $7 \%$ in IDFU group.

Table2: Demographic information and clinical characteristics of patients groups

\begin{tabular}{|c|c|c|c|}
\hline \multicolumn{2}{|c|}{ Demographic } & Patients (NIDFU) & Patients (IDFU) \\
\hline \multicolumn{2}{|c|}{ Number } & 25 & 30 \\
\hline \multicolumn{2}{|c|}{ Gender (male/female) } & $15 / 10$ & $22 / 8$ \\
\hline \multicolumn{2}{|l|}{ Age (y) } & $36-65$ & $40-65$ \\
\hline \multicolumn{2}{|c|}{ Duration of disease $(y)$} & $10.6 \pm 5$ & $12.24 \pm 5.67$ \\
\hline \multirow{3}{*}{$\begin{array}{l}\text { Treatment } \\
(\%)\end{array}$} & Insulin & 40 & 43 \\
\hline & OHD & 40 & 27 \\
\hline & Insulin+OHD & 20 & 30 \\
\hline \multicolumn{2}{|c|}{ Vasculopathy (\%) } & 16 & 13 \\
\hline \multicolumn{2}{|c|}{ Neuropathy (\%) } & 100 & 100 \\
\hline \multicolumn{2}{|c|}{ Retinopathy (\%) } & 64 & 20 \\
\hline \multicolumn{2}{|c|}{ Nephropathy (\%) } & 20 & 7 \\
\hline \multicolumn{2}{|c|}{$\operatorname{BMI}\left(\mathrm{kg} / \mathrm{m}^{2}\right)$} & $29.72 \pm 4.7$ & $31.2 \pm 10.68$ \\
\hline \multicolumn{2}{|c|}{ FSG (mg/dl) } & $252.64 \pm 98.73$ & $258.5 \pm 104.03$ \\
\hline \multicolumn{2}{|l|}{ HbA1c $(\%)$} & $9.54 \pm 1.49$ & $10.18 \pm 1.12$ \\
\hline
\end{tabular}


Low hemoglobin levels in infected diabetic foot ulcer

\begin{tabular}{|c|c|c|}
\hline $\mathrm{TC}(\mathrm{mg} / \mathrm{dl})$ & $197.28 \pm 43.67$ & $199.77 \pm 37.47$ \\
\hline $\mathrm{TG}(\mathrm{mg} / \mathrm{dl})$ & $183.32 \pm 31.15$ & $255.67 \pm 59.78$ \\
\hline HDL-C $(\mathrm{mg} / \mathrm{dl})$ & $38.11 \pm 8.67$ & $33.29 \pm 6.97$ \\
\hline LDL-C (mg/dl) & $122.48 \pm 40.01$ & $115.3 \pm 34.44$ \\
\hline VLDL-C $(\mathrm{mg} / \mathrm{dl})$ & $36.68 \pm 6.32$ & $51.2 \pm 12^{* *}$ \\
\hline $\mathrm{ESR}(\mathrm{mm} / \mathrm{hr})$ & $25.2 \pm 14.26$ & $76.73 \pm 33.39^{* *}$ \\
\hline RBC & $4.94 \pm 0.67$ & $4.24 \pm 0.55^{* *}$ \\
\hline $\mathrm{Hb}(\mathrm{g} / \mathrm{dl})$ & $13.45 \pm 2.15$ & $10.34 \pm 2.17^{\text {*2: }}$ \\
\hline PCV (\%) & $40.46 \pm 5.65$ & $35.03 \pm 5.52^{* *}$ \\
\hline $\mathrm{MCV}(\mathrm{Fl})$ & $81.96 \pm 3.26$ & $83.57 \pm 6.09$ \\
\hline $\mathrm{MCH}(\mathrm{Pg})$ & $27.2 \pm 2$ & $27.24 \pm 2.87$ \\
\hline MCHC $(\mathrm{g} / \mathrm{dl})$ & $33.09 \pm 1.58$ & $32.55 \pm 1.91$ \\
\hline RDW (\%) & $10.92 \pm 0.94$ & $11.19 \pm 0.99$ \\
\hline $\begin{array}{l}\text { PLT } \\
\end{array}$ & $244.4 \pm 62.8$ & $301.9 \pm 61.65^{* *}$ \\
\hline MPV (Fl) & $7.03 \pm 1.2$ & $6.71 \pm 1.25$ \\
\hline
\end{tabular}

As shown in table (3), and Fig.1, ESR level shows a significant negative correlation with RBC, Hb, PCV and MPV in IDFU group. While, ESR level shows a significant positive correlation with PLT in IDFU group (Fig.2).

Table (3): Pearson correlation of ESR with hematological parameters in IDFU group

\begin{tabular}{|l|l|l|}
\hline \multirow{2}{*}{ Parameter } & \multicolumn{2}{|c|}{ ESR $(\mathrm{mm} / \mathrm{hr})$} \\
\cline { 2 - 3 } & r & $\boldsymbol{P}$ \\
\hline $\mathrm{RBC}$ & -0.386 & $0.035^{*}$ \\
\hline $\mathrm{Hb}(\mathrm{g} / \mathrm{dl})$ & -0.386 & $0.035^{*}$ \\
\hline $\mathrm{PCV}(\%)$ & -0.4 & $0.029^{*}$ \\
\hline $\mathrm{MCV}(\mathrm{Fl})$ & -0.274 & 0.143 \\
\hline $\mathrm{MCH}(\mathrm{Pg})$ & -0.302 & 0.105 \\
\hline $\mathrm{MCHC}(\mathrm{g} / \mathrm{dl})$ & -0.213 & 0.258 \\
\hline RDW $(\%)$ & 0.097 & 0.609 \\
\hline PLT & 0.404 & $0.027^{*}$ \\
\hline MPV $(\mathrm{Fl})$ & -0.387 & $0.035^{*}$ \\
\hline
\end{tabular}

*Correlation is significant at $P<0.05$

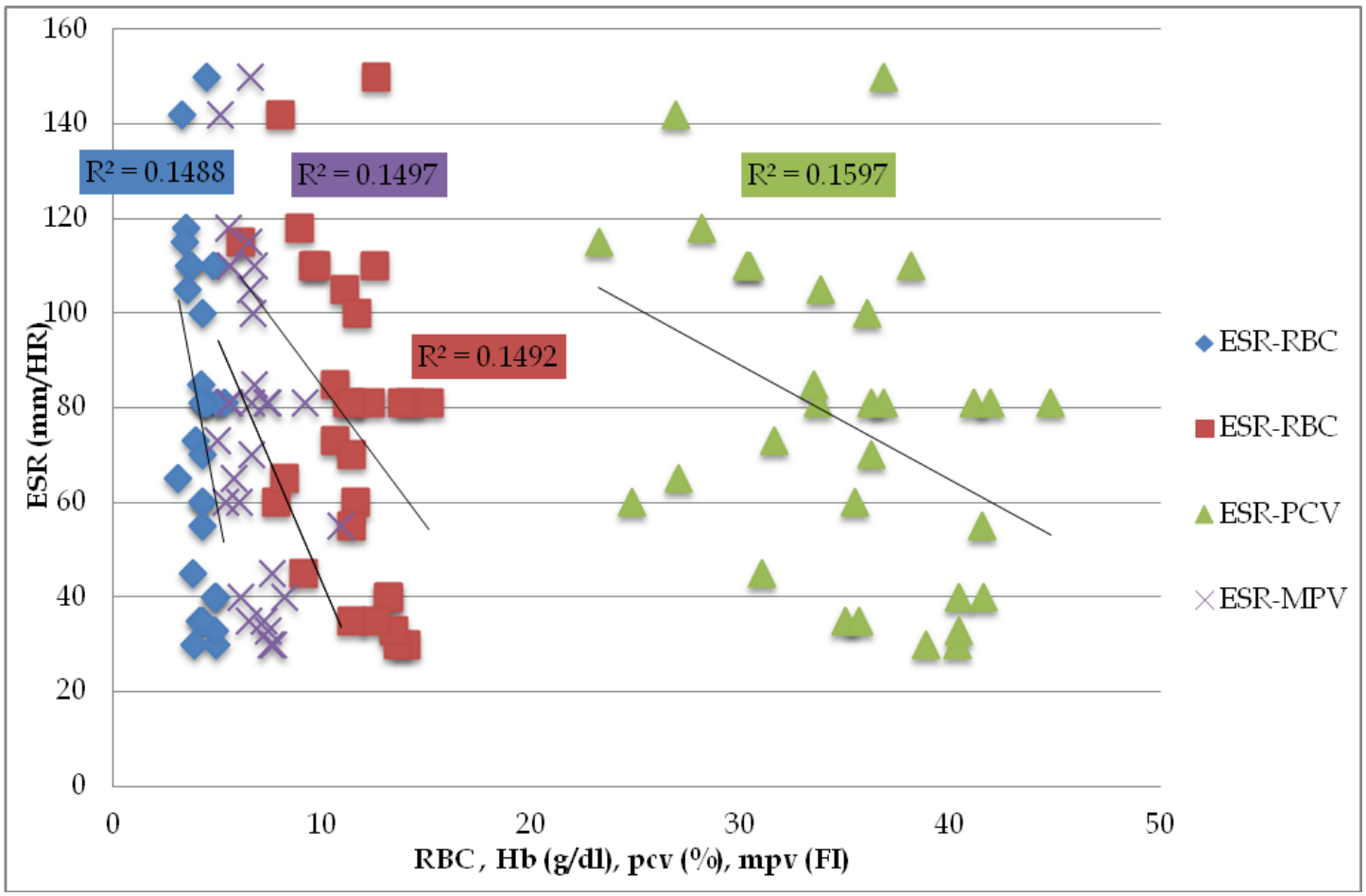

Figure (1): Pearson correlation of ESR with RBC, Hb, PCV and MPV in IDFU group. 


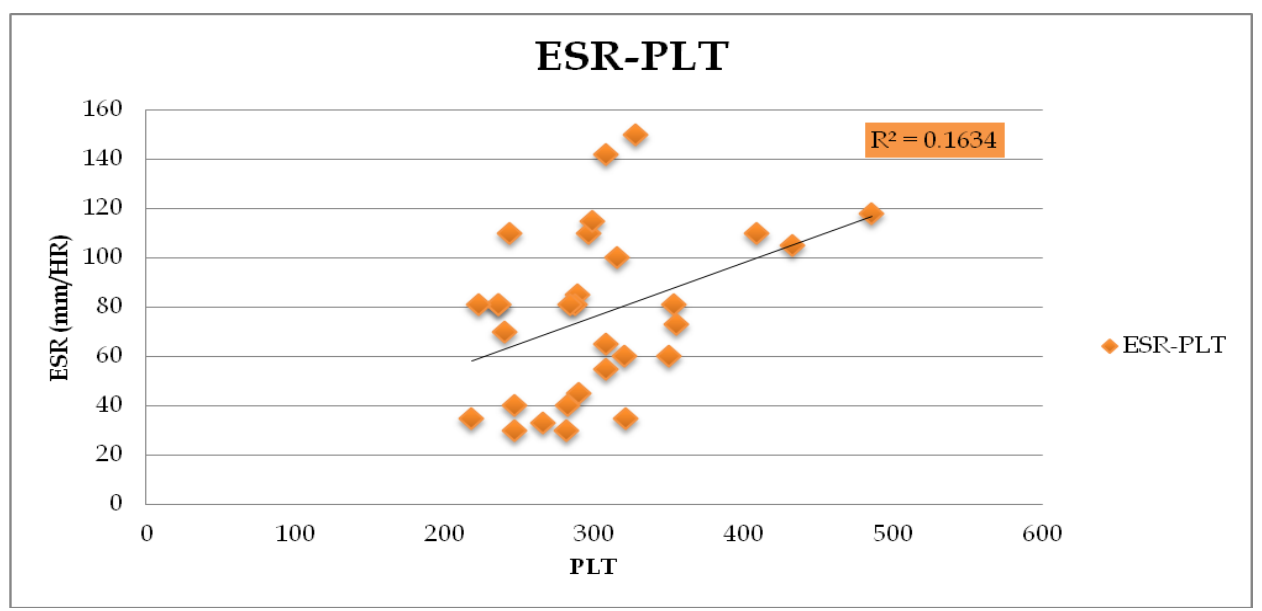

Figure (2): Pearson correlation of ESR with PLT in IDFU group.

\section{Discussion}

Vascular complications of diabetes (nephropathy, retinopathy, and neuropathy) are associated with anemia that may lead to impaired wound healing, and macrovascular disease ${ }^{[16]}$. It was suggested that low blood oxygen level accompanying low hemoglobin levels may consequently worsen ischemia of the lower limb. Gene expression of endothelial adhesion molecules may happen due to induced hyperkinetic circulation by anemia which ultimately may generate thrombosis ${ }^{[17]}$. Anemia has been severally reported as a complication of diabetes mellitus ${ }^{[18]}$. According to previous studies, the proteins of RBC membrane undergo oxidation through non-enzymatic glycosylation due to increased oxidative stress in diabetes and reduce PCV, $\mathrm{Hb}, \mathrm{RBC}$ levels that may lead to hemolysis and consequently to anemia ${ }^{[19,20,21]}$. It has been suggested that the rough utilization of angiotensin changing enzyme inhibitor (ACEI) inhibit the pro-erythropoeitic effects of angiotensin II on erythrocyte precursors, which may cause anemia in DM ${ }^{[22,23]}$. The relationship between anemia and DFU are inadequately understood. A previous retrospective study suggested the existence of a relationship between anemia and clinical stages of DFU ${ }^{[18]}$. We found that $63 \%$ of IDFU patients have anemia which is in agreement with previous studies where $57 \%$ of 47 patients with DFU (2-3 Wagner grade) were anemic ${ }^{[24]}$, while in a study enrolled all Wagner grades (1-5), the percent of anemia was $62 \%$ of 42 patients with DFU ${ }^{[25]}$. Fengning et al. (2016) ${ }^{[26]}$ study the variables in the DFU patients with and without anemia. They noted that almost $50 \%$ of the diabetic foot patients have low hemoglobin levels, and concluded that anemia is common in patients with DFU and is associated with substantial morbidity and mortality. Thomas and Rampersad (2004) ${ }^{[27]}$ had similar findings whereby the prevalence of anemia was higher in diabetic patients in spite of having safeguarded renal function. According to Avivit et al. $2015^{[28]}$ study, they measured deformable RBC in diabetic patients with and without DFU. They found significant increase in the of deformable RBCs percent in DFU patients in comparison with that in patients without DFU. Suggesting that this increase may slow blood flow in blood vesicle and delay wound healing. High levels of glycated hemoglobin have been appeared to impair endothelium mediated vaso- active responses, which can prompt hypertension and vascular diseases in diabetic patients ${ }^{[29]}$. Micro-angiopathy is a result of changes in the microcirculation which is caused by changes in blood viscosity and red blood cell deformability ${ }^{[30]}$. One of the variables deciding the cell deformability is the erythrocyte cytoplasmic viscosity that is basically determined by the properties and the concentration of hemoglobin in the erythrocyte ${ }^{[31]}$. Many factors were suggested as causing the frequent onset of anemia, including chronic inflammation, diabetic nephropathy, and malnutrition. Chronic inflammation is considered to be a common cause of anemia in diabetic patients, especially with $\mathrm{DFU}{ }^{[32]}$. An explanation presented by Richards (2012) ${ }^{[33]}$ which associate the inflammatory state with anemia. The transport of iron to the bone marrow is inhibited due to the scavenging of iron by macrophages and its storage in ferritin.

Wright et al. (2014) ${ }^{[31]}$ found the prevalence of anemia in patients with severe DFU. Their explanation was due to systemic inflammation, repeated superficial, deep tissue infection, osteomyelitis, and antibiotic use which may delay healing of foot ulcer. Our finding of ESR correlated negatively with $\mathrm{Hb}$ is most likely related to the inflammatory and infective processes occurring in DFU which is in agreement with the result of khanbhai et al. (2012) ${ }^{[34]}$. They found an inverse correlation between hemoglobin and CRP, and they suggested that the progression of foot ulcer was related to decreased hemoglobin level and increased CRP level. The limitation of the study was small sample size which may be due to limitation of clinical centers available for diabetic foot ulcer care. Also most patients do not recruited to these centers, because they visit private clinics for wound treatment. 


\section{Conclusion}

This prospective study showed a high incidence of anemia in patients with severe DFU. Negative correlation between ESR and $\mathrm{Hb}$ was found. Iron replacement and therapeutic strategies are recommended to improve their health and quality of life.

\section{Acknowledgements}

Our deep gratitude is due to all patients and staff member of laboratories in National Center of Diabetes, National Center of Hematology and Al-Yarmuk Teaching hospital.

\section{References}

[1] S.P. Pendsey, Understanding diabetic foot, Int J Diabetes Dev Ctries, 30, 2010, 75-79.

[2] G.E. Reiber, The epidemiology of diabetic foot problems, Diabet Med, 13 (1), 1996, 6-11.

[3] A.L. Carrington, S.K. Mawdsley, M. Morley, J. Kincey and A.J. Boulton, Psychological status of diabetic people with or without lower limb disability, Diabetes Res Clin Pract, 32, 1996, 19-25.

[4] C.M. Clark and D.A. Lee, Prevention and treatment of complications of diabetes mellitus, N Engl J Med, 332, 1995, $1210-17$.

[5] D. Singh, P. Winocour and K. Farrington, Erythropoietic Stress and Anemia in Diabetes Mellitus, Nature Reviews Endocrinology, 5, 2009, 204-210.

[6] M. Thomas, C. Tsalamandris, R. MacIsaac and G. Jerums, Anaemia in Diabetes: An Emerging Complication of Microvascular Disease, Current Diabetes Reviews, 1, 2005, 107-126.

[7] V.J. Teodorescu, C. Chen, N. Morrissey, P.L. Faries, M.L. Marin and L.H. Hollier, Detailed protocol of ischemia and the use of noninvasive vascular laboratory testing in diabetic foot ulcers, Am J Surg., 187, 2004, 75S-80S.

[8] B. Conway, R. Miller, R. Klein and T. Orchard, Prediction of Proliferative Diabetic Retinopathy with Hemoglobin Level, Archives of Ophthalmology, 127, 2009, 1494-1499.

[9] M. Singh, S. Shin, Changes in erythrocyte aggregation and deformability in diabetes mellitus, Indian Journal of Experimental Biology, 47, 2009, 7-15.

[10] M. Ayman., Mahmoud, Hematological alterations in diabetic rats- role of adipocytokines and effect of citus flavonoids , Excli Journal, 12, 2013, 647-657.

[11] A. Nadeem, AK. Naveed, MM. Hussain and SI. Raza, Correlation of inflammatory markers with type 2 Diabetes Mellitus in Pakistani patients, J Postgrad Med Inst, 27, 2013, 267-73.

[12] American Diabetes Association, Diabetes Care, 38(Suppl 1), 2015, 8-16.

[13] K. Bakker, J Apelqvist and N.C. Schaper, International Working Group on Diabetic Foot Editorial Board. Practical guidelines on the management and prevention of the diabetic foot 2011, Diabetes Metab Res Rev., 28(suppl 1), 2012, 225-231.

[14] E. McLean, M. Cogswell, I. Egli, D. Wojdyla and B. de Benoist, Worldwide prevalence of anemia, WHO Vitamin and Mineral Nutrition Information System 1993-2005, Public Health Nutr., 12, 2009, 444-454.

[15] W.T. Friedwald, R.I. Levy and D.D. Fredickson, Estimation of the concentration of low density lipoprotein cholesterol in plasma without use of the preparative ultra-centrifugation, Clin Chem., 18, 1972, 499-02.

[16] A. Abate, W. Birhan and A. Alemu, Association of anemia and renal function test among diabetes mellitus patients attending Fenote Selam Hospital, West Gojam, Northwest Ethiopia: a cross sectional study. BMC Hematology, 13(1), 2013, 6.

[17] H. Milionis, V. Papavasileiou , A. Eskandari, S. D’Ambrogio- Remillard, G. Ntaios and P. Michel, Anemia on admission predicts shortand long-term outcomes in patients with acute ischemic stroke, Int J Stroke., 10, 2015, 224-230.

[18] R. Kothari and P.A. Bokariya, Comparative Study of Haematological Parameters in Type 1 Diabetes Mellitus Patients \& Healthy Young Adolescents, Int. J.Biol Med Res., 3(4), 2012, 2429-32.

[19] S.O. Oyedemi, E.A. Adewusi, O.A. Aiyegoro and D.A. Akinpelu, Antidiabetic and Hematological Effect of Aqueous Extract of Stem Bark of Afzelia africana (Smith) on Streptozotocin-Induced Diabetic Wistar Rats, Asian Pac.J.Trop.Biomed, 1(5), 2011, 353-58

[20] R.K. Mohammed, S. Ibrahim, S.E. Atawodi, E.D. Eze, JB.Suleiman and I.S. Malgwi, Anti-diabetic and Haematological Effects of n-Butanol Fraction of alchornea cordifolia Leaf Extract in Streptozotocin-Induced Diabetic Wistar Rats, Scientific Journal of Biological Science, 2, 2013,3 .

[21] E.K. Uko, O. Erhabor, L.Z. Isaac, Y. Abdulrahaman. T.C. Adias, Y. Sani, R.S. shehu, H.M. Liman, M.K. Dalhtu and A.S. Mainasara, Some Haematological Parameters in Patients with Type - I Diabetes in Sokoto, North Western Nigeria. J. Blood Lymph , 3, 2013, $2165-7831$.

[22] I.A. Babatunde, D. Uchechukwu, O.E. Chinwe, A.O. Abduffatah, T.M. Azukaego, A.E. Tosan, U. Esmond and N.N. Isaac., Incidence and risk of anemia in type 2 diabetic patients in the absence of renal impairment, Health, 4, 2012, 304-308.

[23] K.P. Marathias, B. Agroyannis, T. Mavromoustakos, J. Matsoukas and D.V. Vlahakos, Hematocrit-lowering effect following inactivation of rennin-angiotensin system with angiotensin converting enzyme inhibitors and angiotensin receptor blockers, Curr Top Med Chem, 4, 2014, 483-486.

[24] O.A. Ogbera, E. Osa , A. Edo , E. Chukwum , Common clinical features of diabetic foot ulcers: perspectives from a developing nation, International Journal o Lower Extremity Wounds, 7(2), 2008, 93-98.

[25] C.O. Ekpebegh , S.O. Iwuala, O.A. Fasanmade, A.O. Ogbera, E. Igumbor and A.E. Ohwovoriole, Diabetes foot ulceration in a Nigerian hospital: in-hospital mortality in relation to the presenting demographic, clinical and laboratory features, International Wound Journal, 6 (5), $2009,381-385$

[26] C. Fengning, Z. Min, Y. Yang, T. Wenqing, H. Xiaoqun and Z. Bo., Anemia in Patients with Diabetic Foot Ulcer: Prevalence, Clinical Characteristics, and Outcome. The International Journal of Lower Extremity Wounds, 27, 2016, 1-7.

[27] S. Thomas and M. Rampersad, Anemia in diabetes, Acta Diabetologica, 41, 2004, 13-17.

[28] A. Cahn, L. Livshits, A. Srulevich, I. Raz, S. Yedgar and G. Barshtein, Diabetic foot disease is associated with reduced erythrocyte deformability, Int Wound J., 13, 2016, 500-4, 2016.

[29] M.R. Ahmed, G.A. Ibrahim, H.G. Baker and T.E. Meawed, Assessment of C-Reactive protein and Macrophage Migration Inhibitory Factor in Diabetic Foot Infection, Afro-Egypt J. Infect. ENDEM., 1, 2011, 19-27.

[30] Y. Cho, M. Mooney and D. Cho, Hemorheological disorders in diabetes mellitus. Journal of diabetes science and technology, 2, 2008, 11301138 .

[31] J.A. Wright, M.J. Oddyand T. Richards, Presence and Characterization of Anemia in Diabetic Foot Ulceration. Anemia, 1-8, 2014.

[32] WHO, Hemoglobin Concentrations for the Diagnosis of Anemia and Assessment of Severity, 2011.

[33] T. Richards, Anaemia in hospital practice. The British Journal of Hospital Medicine, 73(10): 571-575, 2012.

[34] K. Mustafa, L. Stavros, W. Josephine, H. Steven and R. Toby, Anemia, inflammation, renal function, and the diabetic foot: What are the relationships?. The diabetic foot journal, 15(4), 2012, 150-158. 